\title{
Depression in children and teenagers
}

\author{
Iliadis Ch. ${ }^{1, *}$, Papadopoulou L. ${ }^{2}$, Papoulia F. ${ }^{3}$ \\ ${ }^{1}$ Nursing Department of Alexander Technological Educational Institute of Thessaloniki, Thessaloniki, Greece \\ ${ }^{2}$ General Hospital of Thessaloniki "Agios Pavlos", Thessaloniki, Greece \\ ${ }^{3}$ General Hospital of Thessaloniki “Agios Dimitrios”, Thessaloniki, Greece
}

Email address:

ch.iliadis@yahoo.gr (Iliadis Ch.), lemontritsa@yahoo.gr (Papadopoulou L.), fotinipapoulia@yahoo.gr (Papoulia F.)

\section{To cite this article:}

Iliadis Ch., Papadopoulou L., Papoulia F.. Depression in Children and Teenagers. American Journal of Nursing Science. Special Issue: Mental Health Care: Aspects, Challenges and Perspectives. Vol. 4, No. 2-1, 2015, pp. 92-95. doi: 10.11648/j.ajns.s.2015040201.27

\begin{abstract}
Depression is a psychiatric disease with dominant symptom, disorder of emotion and can affect people of all ages, including children and adolescents. The main feature of depression is the persistent and enduring sadness, the irritability and the absence of interest or satisfaction of any activity. Children and adolescents with depression are usually sad, and generally experiencing similarly the disease with older people. The untreated depression may result in a school failure, alcohol and substance abuse, and suicide. A decisive role for the management of depression in children and adolescents plays both family and school with the help and support of teachers.T he mental health of humans, particularly children, threatened by the disease of our century which is none other than depression, for this reason it is necessary for its cure the family cooperation with the school.
\end{abstract}

Keywords: Depression, children, teenagers

\section{Introduction}

The term depression prevailed during the first decades of the 20th century to replace the term "melancholy" that comes from the ancient Greek concept of "melaena bile." According to this view melaena bile was in the body and its excess was causing melancholy (1). Depression is a psychiatric disease with dominant symptom, disorder of emotion, accompanied by disturbances, of cognitive functions, somatic complaints and difficulties in interpersonal relationships. Depression according to the WHO is the most frequent of diagnosed mental disorder with major social cost. The social importance of the disease is proportional to the degree that the individual is suffering the loss of work, the dissolution of families the escape of diagnosis and the increased physical morbidity and mortality, which causes $(1,2)$. Nearly half of all cases of depression are not recognized and not treated. About $10 \%$ of depressed patients commit suicide. The World Health Organization predicts that by 2020 depression will be the biggest health problem in the developing world disrespecting possibly more than $25 \%$ of the population and by then, the heavy depression will be the second leading cause of death and disability although depression is treatable (3). Depression can occur at any age (from 15 to 70 years), its beginning, however, usually placed in the middle age. The last years, it has been observed that is more common in adolescence or in early adulthood and in children. Depressive episodes that take place in these age groups have been implicated in the increased use of alcohol or other psychoactive substances (4). The multiformity in which it appears, the atypical symptomatology and the ability to imitate any disease, trick many times non-specialists doctors, resulting in only $50 \%$ of patients are correctly diagnosed by general practitioners. Furthermore, the prejudice and stigmatization associated with mental disorders discourage or prevent sufferers to contact with the experts. For this reason often not recognized and cure a diseaset hat may have adverse effects on the personal life of the individual(abuse or substance dependence, causing traffic accidents)as also in family relationships and its professional activities (5). This paper aims to highlight the impact of child and adolescent depression and the need of recognizing and treating of the disease, for preventing extreme behavior by children or adolescents, e.g. suicidal behavior, etc.

\section{Material and Methods}

The material of this study is consisted of recent articles on the topic were found mainly in electronic databases such as Medline and the Greek Academic Libraries Link (HEAL- 
Link), with keywords: depression, suicide, children and adolescents.

\section{Depression}

The term depression in Psychiatry suggests a specific disease, a disorder that causes a combination of symptoms that are not found in other disease (doctors tend to call these combinations of symptoms, as syndromes). One of the characteristics of the syndrome of depression is the bad mood. In depression feeling can be worse in the morning than in the evening, while in normal people who just feel upset, the mood is usually better when getting up in the morning $(1,6)$. Depression can have catastrophic consequences in the life of the person, who is suffering, as well as his family and his relations with others. It can lead to a substantial drop in productivity and work performance(over $30 \%$ ), to the divorce (the divorce index in middle-aged men is much higher than other age groups and depression has been shown to be the main underlying cause of divorce), and even to suicide. The suicide index for men aged 40-60 years is three times higher than the average -and $80 \%$ of all suicides are committed by men (7). Women develop depression almost twice more often than men. That difference is not fully explained. This may be due to the fact that women can admit more easily than men their depressive symptoms. The difference is quite large, so it is believed that a combination of biological and psychosocial factors contributes to higher frequency. (8)Recent researches show that men are equally possible to suffer from depression as women, if not more. However, they are less likely to seek help from their environment or from a specialist Depression in men is often not recognized by the person himself, his family, and even from their general practitioners, because it is covered under other conditions. Nevertheless, some scholars estimate that the rate of depression in middle aged men reaches $40 \%$, percentage significantly higher than that seen in women $(25 \%)(9)$. The differences between the sexes to the appearance of depression are also due to cultural factors that have to do with how the man understands his role. The way in which men think about themselves is not much help in addressing the problem. Compared to women, tend to deal more with how to be competitive, strong and successful. Most men would not like to admit that they feel fragile and vulnerable and therefore are less likely to talk about their feelings with their friends, their family, or their doctor. This probably is the reason for not seeking help when they are depressed. Men tend to believe they must rely on themselves and that is somehow a sign of weakness to have to rely on someone else, even for a short time. Often, instead of talking about how they feel, perhaps they try to feel better by using alcohol or other drugs (10). In the last decades many children suffering from the disease although many believe that only affects adults.

\section{Depression in Children and Teenagers}

Depression is a serious health problem that can affect people of all ages, including children and adolescents. The main feature of depression is the persistent and the enduring sadness the irritability and the lack of interest or satisfaction of any activity. These symptoms are accompanied by a number of other symptoms that affect appetite, sleep, activity levels and concentration, the person's self-confidence and image of himself. Clinical depression is very different from the feeling of bad mood or the sadness or bereavement feelings that often accompany the loss of a loved person. Depression is not caused by personal weakness of the individual neither in features of his personality.This is a mental illness that affects the whole body and has impact on the way a person feels, thinks and behaves (11). Children and adolescents with depression are usually sad, and generally experiencing similarly the disease with older people. The untreated depression can result in school failure, alcohol and substance abuse, and suicide (12). Approximately 3\% of all children may exhibit depression. The treatment of depression in children and adolescents is as effective as the treatment of depression in adults. Depression in a large percentage is hereditary, although the experiences of each child can play an important role. The younger the child at the beginning of the disease, the more difficult the prognosis. Studies have shown that one in five children have been diagnosed with mental, emotional or behavioral disorder. With depression have been diagnosed one in thirty-three children and only one in eight adolescents have experienced symptoms of depression. According to surveys girls are more likely to experience depressive episode than boys and children with chronic disease or children who have suffered a traumatic episode are more likely to develop depression (13).

\section{Risk Factors and Symptoms}

Children who for some reason, are in a state of stress, have experienced a significant loss, have learning disabilities or behavioral problems are more likely to develop depression. Children, who experience clinical depression, usually come from families with a history of depression. (14)The child is often sad and desperate. Specifically, most days of the week and for several hours the child is crying and is sad. A typical symptom that may worry their parents are the away from their friends and their activities which the child derive pleasure and satisfaction in the past. The child does not visit his friends any more, or makes no friends and spends most of his time alone, while activities like game have no longer interest. The child who is suspected of developing depression has increased irritability, and the smallest difficulties bring frustration and anger that the child cannot manage. Often the depressed child appears feeling of guilt and impotence. The child uses phrases such as "I'm stupid" or "I blame for all" , which did not use before. (15)Also, the many absences and the reduction in school performance should worry parents for appearance depression in their child. When the child loses many lessons because does not want to go to school or when the performance falls very sharply then parents should think about the mental health of their child. Another symptom that 
characterizes the depressed child is the change in eating habits. Nutrition plays an important role in maintaining good health and is closely related to social, cultural and symbolic messages. $(16,17)$ The increase or the decrease of appetite and the change in dietary habit requires a depressive episode. Due to the change in eating habits the child complains of frequent headaches and stomach aches. In this contributes the sleep problems such as frequent waking during the night. (18)Finally, the ignorance, the idleness, the lack of concentration and the indecisiveness are characteristic findings of depression, like other mental illnesses (19). The children who were well organized in the past seem to forget or cannot organize their time and their activities or cannot concentrate on what they do should trouble their parents for probable depression (20).

\section{The Role of the School in Treatment of Depression}

Schoolchildren have the ability to describe symptoms like negative mood(they do not want to be anything when they grow up), difficulty in concentration, poor performance in school, irritable mood, crying and suicidal thoughts, for which parents often do not know. There is a myth that children do not commit suicide, so the suicide attempts are characterized by pediatricians as accidents. $(21,22)$ Teachers spend much time with students and therefore are an important source of information for the mental health of children and the early detection of signs and symptoms of depression. Teachers (compared with parents) are also able to observe a range of normal behaviors of children and to identify with greater convenience any significant developmental and behavioral deviations. $(23,24)$ At the same time, beyond the identification and the assessment of depressive symptoms, the school place is indicated for their effective response. $(25,26)$. School is the prime place where there is access to all children where can be applied to mental health promotive programs in the total student population. Researches have proved that one in thirty students may be relieved of the symptoms of depression when early evaluation and treatment have be endone from the school. (25)Therefore the role of the school in the treatment of depression is crucial. The existence of minimum mental health services outside the school makes the school the most important place in which mental health services can be provided to the students $(27,28)$.

\section{The Role of the Family in the Treatment of Depression}

The family is the first group in which the child becomes a member .In this group for the first time are interwoven the bio-psychological and the social factors that affect individual behavior. If parents or other adult persons in the life of a child or teenager suspect the existence of depression, should seek expert help. The depression is treated. Early diagnosis and treatment of depression in children is very important. Diagnosis is based through assessment of the child and his family and with the help of psychological tests. More generally, the cooperation of the family and the school environment is essential and necessary for the treatment of depression in children. (29)Many times, the child expresses in depression the problem that exists in the family. Therefore it is very important the diagnostic assessment of the whole family or the collection of information on the conditions, relationships and family dynamics. Often, counseling and psychotherapeutic treatment of parents has the power to heal the child's depression. The change of attitudes, perceptions and behaviors through family meetings with psychotherapists is essential. (30)The individual psychotherapy of the child may also have good results. New psychotherapeutic approaches such as play therapy can help the child to process the depressing feelings through play. Medication is given rare in children in very severe forms of depression commonly coexist with organic causes (other diseases) (31).

\section{Conclusions}

The adolescent depression is a very serious public health problem and has been thoroughly investigated in order to allow the prevention ,through programs promotion of mental health. The supportive family environment, trust and honest communication in the family, active parental supervision, good relationship with peers and teachers and academic success, are important adolescent enhancing agents.

\section{References}

[1] Siklafidou P., Zeleni D., Livanitis M. Transcultural Psychiatry and Depression. Brain,2011; 48(4): 146-150.

[2] Burns, D. D., Feel good! Publishing Pataki, Athens, 1997.

[3] Anonymous. Depression.A vailable at: http://www.who.int/topics/depression.[accessed 30/10/2014].

[4] Petruzzelo S J., D.M. Landers, B.D. Hatfield, K.A. Kubitz, $\& W$. Salazar, A meta-analysis on the anxiety-reducing effects of acute and chronic exercise. Sports Medicine,1991; II (3).

[5] Anonymous. Depression. Available at: http://www.katathlipsi.gr. [accessed30/10/2014].

[6] Papageorgiou Ch., Anagnostopoulos D., Masdrakis B.,Mperatis I., Kontoaggelos K., "Depression: The many faces of a problem," National Documentation Centre,http://www.eie.gr/epistimiskoinonia/20102011/z_cycle.pdf, 24-May-2011.

[7] Douzenis A., Ferentinos P., Likouras E., Depression and delinquency. Archives of Greek Medicine, 2005; 22(6): 535543.

[8] Likousa M.,Papadopoulos A., Vretos I., Kamposioras K., Pappa E., Andriopoulos P., \&NiakasD.,Rating frequency of depression in patients in primary care,Archives of Greek Medicine2012;29(1): 77-84. 
[9] Anonymous .Depression. Available athttp://www.ipsyxologos.gr.[accessed 30/10/2014].

[10] Manou N.,Basics of clinical psychiatry ,UniversityStudioPress 1988.

[11] Lazaratou E., Anagnostopoulos D.K. ,Adolescence and depression, Archives of Greek Medicine, 2011;8(5):466-474.

[12] Botsari M.E. Modern problems of adolescents. Available athttp://repository.edulll.gr.[accessed 31/10/2014].

[13] Kolaitis G.The disturbances of mood in childhood and adolescence: continuity and discontinuity in adulthood.Psychiatry, 2012;23: 94-100

[14] Kakouros E., Maniadakis K.,Psychopathology in children and adolescents. Development approach.PublishingDardanos Athens, 2006

[15] Petruzzelo S.J., D.M. Landers, B.D. Hatfield, K.A. Kubitz, and W. Salazar, A meta-analysis on the anxiety-reducing effects of acute and chronic exercise, Sports Medicine, 1991; II(3).

[16] Tsaloglidou A., Rammos K., Kiriklidis K., Zourlandani A., Matziari C., Nurse's ethical decision-making role in artificial nutritional support. BJN, 2007;16(16):996-1001.

[17] KourkoutaL, RarraA, Abrahim.E., The diet of children in school age, Scientific Chronicles, 2013; 18 ( 2 ) :78 -82.

[18] Kaplan HI, Sadock BJ, Grebb JA. Psychiatry ,vol 2, $7^{\text {th }}$ Edition.MedicinePublishingLitsas, Athens, 2000.

[19] Tsaloglidou A., Matziari Ch., Eating disorders and nursing interventions in Alzheimer's disease,2005; 47 (4): 439-446.

[20] Patersen AC, Compas BE, Brooks- Gunn J, Ey S, Grant KE. Depression in adolescence. American Psychologist, 1993; 48: 155-168.

[21] Tisher M. , Teacher's assessments of prepubertal childhood depression. Australian Journal of Psychology,1995; 47(2): 9396.
[22] Velentza O, Fradelos E, Vlahothanasi E, Athanasiadis E, Kourkouta L. The role of the nurse in the management of anxiety. $2^{\text {nd }}$ National Conference of Mental Health, Athens, 18$20-12-2014$.

[23] Kirchner, J. E., Yoder, M. C., Kramer, T. L., Lindsey, M. S., \& Thrush, C. R. Development of an educational program to increase school personnel's awareness about child and adolescent depression. Education, 2000; 121(2): 235-246.

[24] Taggart, L., \& McMullan, P. An exploratory study of teacher's knowledge about the symptoms of depression in young people with and without intellectual disabilities. JournalofIntellectualDisabilities, 2007; 11(2): 183-195

[25] Poulou M.S., Depressive symptoms in preschool children: detection list for teachers.HellenicJournalofPsychology, 2013;10: 147-167.

[26] Fradelos E., Papathanasiou I., Kleisiaris Ch., Kourkouta L., The use of gis as a decision making tool in mental health practice. International Congress of the World Federation for Mental Health and The Hellenic Psychiatric Assosination "Living with Schizofphrenia" 9-11 October, Athens, Greece.

[27] Kourkouta L, Mavroidi A, Rarra A. Dance as a therapeutic mean for children. 1st International Balkan Conference on Health Sciences. Edirne, Turkey. Abstract Book. May 14 - 16 2014.

[28] Kourkouta L., Rarra A., Mavroeidi A., Prodromidis K. The contribution of dance on children's health.ProgHealthSci 2014; 4(1): 229- 232 .

[29] Children's Depression. Available athttp://gonis.gr.[accessed 31/10/2014].

[30] Herbert, M. ,Psychologically childhood problems, Greek Letters, Athens, 1996

[31] Tsaousoglou A, Koukourikos K.,Quality and health services. Stigma Publishing, 2007;15(1): 18 -24 